\title{
Formation of Social Interaction Competence of Students in Academic Achievements
}

\author{
Tazieva Z.N. \\ Department of physical education and sports \\ Kazan state University of architecture and construction \\ Kazan, Russia \\ ZT89297263435@mail.ru
}

\author{
Galimzyanova I.I. \\ Kazan State Conservatory \\ Kazan, Russia \\ illagalim@rambler.ru
}

\begin{abstract}
The article deals with the problems of students social interaction competence formation in academic activities, the place and significance of this competence among other social competencies, as well as the influence of the social interaction competence on the development of a future specialist (using individual specialties as an example). In addition, the article draws attention to the organization of social interaction experience, which is a pressing issue in modern pedagogical science. The author gives the definition of the concept "social interaction competence".
\end{abstract}

Keywords - the formation of social interaction competence; academic achievements; social competences; organization of social interaction; the professional development of a future specialist; competence approach.

\section{INTRODUCTION}

The relevance of the problem lies in the fact that the formation of social competencies occupies a special place in training a would-be professional, since adaptation in society - in a social medium, in a professional team is essential for a person, and the task of a university lecturer in this case is to facilitate to the utmost this process. Instructors and lecturers have to strive to form such a socially prepared personality who would most effectively interact with other people.

In modern pedagogics, the main approach to the organization of training (at all levels) is the competence approach. In this regard, a special place in pedagogical science is the problem of analysis and the formation of individual competencies. This problem is quite wide ranging, as it affects not only higher education, but also secondary, and elementary, and pre-school education. In addition, the number of competencies is quite large. The peculiarities of the competence-based approach vary considerably, taking into account the age peculiarities of students: for example, the methods of competences formation in university students and in high school students are completely different. The same can be said about the nature of universities themselves, since the methods used in technical universities are strikingly different from those used in universities of humanities.

\section{LITERATURE REVIEW}

The importance of social interaction, the formation of such competence among students was more than once emphasized by researchers and teachers. And although many of them do not single out the competence of social interaction into a separate category, they nevertheless call it key competence in the category of social competences.

We will not dwell in detail on the definition of the concept "competence", since it has repeatedly been the subject of numerous scientific papers. We only note that in neither Russian nor foreign pedagogical science there is any unanimously shared vision as to this definition concept. However, the development of this issue involved such serious researchers as A. V. Khutorskoy, I.A. Zimnaya, V.I. Slobodchikov, E.O. Permyakov, N.A. Goncharova, Z.F. Zeer. In foreign pedagogics, K. Keen and R. White tried to deduce a single definition of the concept "competence" [1].

The most common definition of the concept is that the pedagogical competence is the combined amount of mastering the essence of training. It is expressed in the student's desire to use the knowledge, skills and abilities, as well as methods of activity to solve theoretical and practical problems in specific life circumstances [2].

There are many classifications of competencies. One of the most correct is the classification of I. A. Zimnaya, who outlines 3 categories of the competences:

a) related to the personality;

b) related to the interaction of the man and the society;

c) related to human activity $[1,3]$.

If we address the second part of the problem under study, then social interaction is understood, as a rule, to be a "twoway process of exchanging actions between two or more individuals, in which the interacting parties are connected by a cyclic causal dependence in order to cause an expected behavior in response, which involves the resumption of the action".

The following interpretation of the concept "competence of social interaction" can be given, based on the definition of 
the concepts "competence" and "social interaction": "The competence of social interaction is the effectiveness of solving social problems arising in real situations in a particular society".

N.M. Kodintsev gives another definition of the social interaction competence. He calls this competence "a system of intellectual and behavioral capabilities of the individual, which provide social activity and the resolution of problem situations of social interaction in human relationships" [4].

\section{RESEARCH METHODOLOGY}

Comparing these two definitions, one can easily single out a characteristic feature of the social interaction competence in both of them: its focus on solving any problematic situation. Hence, it is quite logical to consider that the student's basic criterion for the formation of this competence is his readiness to face difficult situations in a human team, the ability to successfully resolve these situations.

In the structure of competence, most researchers distinguish the following components:

- a motivational component;

- a cognitive component;

- an activity component;

- an axiological component $[1,4]$.

These components are characteristic of the social interaction developed competence, both in the humanities, technical and other types of universities. They can be called general pedagogical competences, although the approaches to their implementation in different types of universities vary considerably.

Thus, the formation of the social interaction competence should be aimed at creating such situations in the academic environment of the university which would overlap with real life conditions. At the same time, the main task of the instructor, the tutor, the lecturer should be to create the most comfortable psychological environment in the student team, a soft, inconspicuous accompaniment, and to help them in resolving the created situations in their studies.

Special attention should also be paid to the words written by V.V. Sarajeva in her article: "When young people leave the walls of a high school and enter the university, a new social situation arises, connected with the emergence of a new circle of friends, new lecturers. And as a result, one of the urgent tasks of the university during this period is to create conditions for effective social interaction of students during the educational process." 1 .

From the above mentioned, it can be concluded that, in addition to focusing on future professional activities, the competence of social interaction is focused on the current situation in the student team. It simultaneously plays a dual

\footnotetext{
${ }^{1}$ Saraeva V.V. "The organization of the experience of social interaction of students at the university as a condition for improving professional competence."
}

role: on the one hand, it is the formation of skills that will come useful in the future, on the other, the creation of such an environment in a team of students that would allow them to realize all their social opportunities as effectively as possible.

It would be safely said that it justifies I.A. Zimnaya's thesis that social competence (a part of which there is also the competence under study) is a key one, because it ensures the normal functioning of a person in the society and is a holistic result of vocational training [6]. However, in our opinion, it would be more correct to call social competence (and with it the competence of social interaction) only one of the key competences, since all the other competences are closely interconnected and the level of one competence formation is necessarily reflected at the level of another.

This is manifested in a number of scientific works on pedagogics. So, V. V. Saraeva, on the basis of the experiment, carried out by her, deduces the direct dependence of the professional competence successful formation on the level of the social interaction formation competence.

At the same time, the feedback is also present: it has been experimentally shown that sufficient formation of professional competence leads to an increase in the level of social competences.

We also note that of all the components of social competence the majority of researchers emphasize precisely the competence of social interaction, which makes it possible to call it a key social competence. And this is quite reasonable: in the process of studying at the university, taking a further professional path, the person (the student, and subsequently, the employee) is in a team, in a kind of micro society, where the interaction of individuals with each other plays the leading role. Consequently, it is the competence of social interaction that comes to the forefront. We do not downplay the role of other social competences; however, we note that, taking into account the peculiarities of human behavior and human needs, special emphasis in the educational environment of the university when forming competencies of social orientation should be placed on social interaction.

However, the process of social interaction is not possible without the inclusion of individuals in the overall activity, by implementing which they set certain goals for themselves and achieve them with the help of taking some actions and operations. This direction is realized with the use of such forms of training as role-playing, situational and business games, social and communication trainings, solving production problems, using dialogue and discussion methods, taking advantage of the project method, training in pairs, etc. All these techniques are laid down in and provided for by the competence approach $[1,6]$.

A special complex of the humanities: psychology, pedagogics, philosophy, social psychology, sociology, political science, culture studies, etc., has a special influence on the development and formation of the social interaction 
competence. All the above forms and methods work most effectively in studying these disciplines.

In addition to academic achievements, extracurricular activities also play an important role in students' life. But here it is necessary to take into account the fact that only a small part of students (about 25-30\%) is engaged in extracurricular activities, and, therefore, the main burden for the formation of this competence still lies with the instructor, the educator and his work with students in the process of studying the discipline. This means that the priority form of work with students on the formation of competence was and remains the form of academic activities.

For the formation of the social interaction competence it is also necessary:

1. to make the principles of humanization, humanitarization, integration as the basis for studying at the university and integrate them with the principles laid down by the reforms of the higher education system; to focus on communication and practice-oriented development.

2. for all participants in the pedagogical process of higher education to explicit social competence in their work.

3 . to fully translate into reality the concept of personcentered learning in accordance with the didactic traditions of the university.

4. to orient the study of all disciplines to professional competence - this will make it possible to develop socially and professionally significant competencies [7].

\section{IV.RESULTS}

In the process of forming the competence of social interaction, when teaching various disciplines, professors and lecturers apply methods of active learning, aimed at the formation of intellectual-gnostic, emotional-reflexive and behavioral parts of professional activity. These parts provide a combination of theoretical knowledge and practical skills. If the competence of social interaction is meant in particular, then it should be noted that it is closely connected with the character of the personality, caused, on the one hand, by genetic features, and on the other, by education and upbringing received earlier. Often the qualities given to people from nature are enhanced in the process of socialization. A positive self-determination serves as the basis for the competence of social interaction.

We concluded that for the most effective formation of the competence under study, the following methods should be rationally applied in conducting practical and seminar classes:

a) an interactive method;

b) imitation methods;

c) a method for analyzing specific situations;

d) a method of dramatization.

Also, most researchers mention social and psychological training as one of the most effective methods of forming the competence of social interaction, because they take into account the personality traits that were laid down in childhood along with the development of social competences at subsequent stages of life.

It should be pointed out that social skills change more easily than the values and motives underlying social behavior. This aspect must be particularly considered when developing a model for the formation of the social interaction competence. And here the personality-oriented approach to training is especially pronounced, making it possible to organize individual work with a definite student and, if necessary, to make a plan for the correction of his earlier established competencies.

D.V. Starkova also writes: "Under the influence of the social environment, the values of the individual, the characteristics of social groups they belong to, are formed: such values as: duty, responsibility, kindness, interest, freedom, mutual understanding, cooperation, justice, person himself, tolerance, support, success, empathy, mercy." ${ }^{2}$ This means that when organizing a work on the formation of competence, it is also necessary to remember the social values resulting from its implementation. And, therefore, we need to understand which of the values will be considered a priority at one or another stage of the competence formation.

\section{CONCLUSIONS}

Having analyzed the works of researchers in Russia and abroad, we can formulate the thesis that the competence of social interaction formed at a sufficient level implies:

1. solving problems to establish communication with other participants in the pedagogical process.

2. the ability to relate their interests and the interests of other people and social groups.

3. the ability to avoid and solve conflicts.

4. the demonstration of respect for the people around them.

5. the ability to cooperate and gently defend their point of view [8].

Also, the analysis of the literature on the problem made it possible to determine the criteria for the formation of social interaction competence. They are reflected in the implementation of the following skills:

- the ability to identify and set goals for social interaction;

- to search and exchange information;

- to analyze social situations, to act accordingly with personal and public benefit;

- to form different schemes of cooperation, to build projects and models of their forms, use them in specific types of activities [1].

\footnotetext{
${ }^{2}$ Starkova D.V. "The essence and role of the competence of social interaction in modern pedagogical science."
} 
integration of students' learning and extracurricular activities, it is extremely difficult to implement this situation in practice, since only a few of them participate in extracurricular activities.

\section{References}

Based on the foregoing, it can be concluded that the process of forming the competence of social interaction is complex, multifaceted, multidimensional. This is reflected in taking into account a variety of factors affecting the competence itself.

A number of factors affect the methodology of the competence formation under study - from the specialization of the university to the state of affairs in the student team. At the same time, the formation of competence consists, as it were, consists of two layers: the formation and correction of the skills that a student already has in order to ensure his comfortable stay in a team and the development of skills that will be needed in his future professional activities.

The main types of educational activities in the formation of the social interaction competence are seminars and practical tutorials, since it is precisely these classes that ensure a closer contact between the student and the lecturer, they expand the possibilities of using methods of personalitycentered learning.

And though the most optimal way to form a full-fledged competence of social interaction, scientists call the
[1] Starkova D.V. "The essence and role of the competence of social interaction in modern pedagogical sciences" // "Modern Pedagogics". Electronic scientific and practical journal. 2013, 11. URL: http: www.pedagogika.snauka.ru

[2] Reference24 // Electronic resource. URL: https://spravochnick.ru

[3] Zimnaya I.A. "Key competencies as an effective target basis of a competence-based approach in a training process. Author's version". M.: Research Center for the problems of high quality training. 2004.

[4] Selivanova O.A., Rodina O.N. "The formation of the competence of social interaction of students in academic activities in a technical university" "Bulletin of Tyumen State University. Humanities research. 2016, vol. 2, 3.

[5] Sarajeva V.V. "The organization of the experience of social interaction of students at the university as a condition for increasing professional competence". Young Scientist. 2015, 7.

[6] Zakharova I.G. "The formation of social competence among university students". Fundamental Research. 2007, 11.

[7] Biktagirova G.F. The formation of social competence of students of pedagogical specialties and fields of training programs". "Modern problems of science and education". 2011, 4.

[8] Karpovich I.A. "The formation of the competence of social interaction in the conditions of receiving professional training at universities". URL: http: www.researchgate.net

[9] Alexsandr S. Kuznetsov. Russian Professor's meeting. Russian Journal of Physical Education and Sport. 2019, 14(1), pp. 17-22. DOI: 10.14526/2070-4798-2019-14-1-18-24 